\title{
Mitral annular hinge motion contribution to changes in mitral septal-lateral dimension and annular area
}

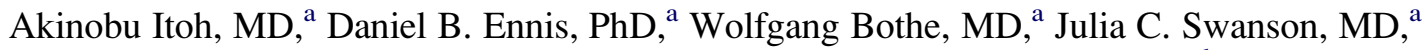 \\ Gaurav Krishnamurthy, MS, ${ }^{a}$ Tom C. Nguyen, MD, ${ }^{a}$ Neil B. Ingels, Jr, PhD, ${ }^{\mathrm{a}, \mathrm{b}}$ and D. Craig Miller, MD ${ }^{\mathrm{a}}$
}

\begin{abstract}
Objective: The mitral annulus is a dynamic, saddle-shaped structure consisting of fibrous and muscular regions. Normal physiologic mechanisms of annular motion are incompletely understood, and more complete characterization is needed to provide rational basis for annuloplasty ring design and to enhance clinical outcomes.
\end{abstract}

\begin{abstract}
Methods: Seventeen sheep had radiopaque markers implanted; 16 around the annulus and 2 on middle anterior and posterior leaflet edges. Four-dimensional marker coordinates were acquired with biplanar videofluoroscopy at $60 \mathrm{~Hz}$. Hinge angle was quantified between fibrous and muscular annular planes, with $0^{\circ}$ defined at end diastole, to characterize its contribution to alterations in mitral septal-lateral dimension and 2-dimensional total annular area throughout the cardiac cycle.
\end{abstract}

Results: During isovolumic contraction (pre-ejection), hinge angle abruptly increased, reaching maximum (steepest saddle shape, change $18^{\circ} \pm 13^{\circ}$ ) at peak left ventricular pressure. During ejection, hinge angle did not change; it then decreased during early filling (change $2^{\circ} \pm 2^{\circ}$ ). Septal-lateral dimension and total area paralleled hinge angle dynamics and leaflet distance (anterior to posterior marker). Pre-ejection septal-lateral reduction was $13 \% \pm 7 \%(3.3 \pm 1.5 \mathrm{~mm})$ from $9 \%$ muscular dimension fall and $18^{\circ} \pm 13^{\circ}$ hinge angle increase.

Conclusions: Pre-ejection increase in hinge angle contributes substantially to septal-lateral and total area reduction, facilitating leaflet coaptation. Semirigid annuloplasty rings or partial bands may preserve hinge motion, but possible recurrent annular dilatation could result in recurrent mitral regurgitation. Long-term clinical studies are required to determine who might benefit most from preserving intrinsic hinge motion without compromising repair durability.

The mitral annulus is an anatomically heterogeneous structure with fibrous and muscular portions. The fibrous annulus is contiguous with the aortic root, includes the fibrous trigones, and subtends the anterior leaflet. The muscular annulus encompasses the anterior and posterior commissures and the posterior leaflet. The annulus has a complex, dynamic shape that contributes to valve function throughout the cardiac cycle. Characterization of the shape and dynamic motion of the fibrous and muscular annular components, however, has been challenging. Recent 3-dimensional (3D) echocar-

From the Department of Cardiothoracic Surgery, ${ }^{\text {a }}$ Stanford University School of Medicine, Stanford, Calif, and the Laboratory of Cardiovascular Physiology and

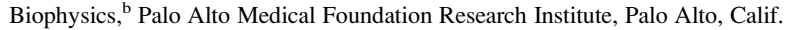

Supported by grants HL-29589 and HL-67025 from the National Heart, Lung, and Blood Institute. A.I., W.B., J.C.S., and T.C.N. were Carl and Leah McConnell Cardiovascular Surgical Research Fellows. A.I. was a recipient of Uehara Memorial Foundation Research Fellowship Award. D.B.E. is supported by National Institutes of Health grant K99-HL087614. W.B. was supported by the Deutsche Herzstiftung Research Fellowship Award. T.C.N. was a recipient of the Thoracic Society Foundation Research Fellowship Award.

Read at the Eighty-eighth Annual Meeting of The American Association for Thoracic Surgery, San Diego, Calif, May 10-14, 2008.

Received for publication May 12, 2008; revisions received Jan 15, 2009; accepted for publication March 23, 2009; available ahead of print Sept 14, 2009.

Address for reprints: D. Craig Miller, MD, Department of Cardiothoracic Surgery, Falk Cardiovascular Research Center, Stanford University School of Medicine, Stanford, CA $94305-5407$ (E-mail: dcm@stanford.edu).

J Thorac Cardiovasc Surg 2009;138:1090-9

$0022-5223 / \$ 36.00$

Copyright (C) 2009 by The American Association for Thoracic Surgery doi:10.1016/j.jtcvs.2009.03.067 diographic and magnetic resonance imaging studies have confirmed the saddle shape of the annulus. Specifically, the fibrous annulus is oblique to the muscular annulus in both human beings ${ }^{1,2}$ and sheep. ${ }^{3}$

Here, the dynamics of the mitral annulus are described by fitting planes to the fibrous and muscular annular regions ${ }^{4,5}$ and then measuring the angle between these planes throughout the cardiac cycle. A previous marker study of annular dynamics with this approach suggested the existence of a hinge axis parallel to a commissure-commissure (C-C) axis near the transition from fibrous to muscular annulus in ovine hearts, ${ }^{4}$ and echocardiographic studies have described a similar hinge in human hearts. ${ }^{5,6}$ To date, however, the relationship between changes in hinge angle $(\Phi)$ and mitral septal-lateral (S-L) diameter and annular area have not been defined clearly.

A better understanding of annular dynamics is needed to provide a rational basis for the design of annuloplasty rings. Currently, there are a wide variety of ring designs available,${ }^{7-11}$ but a consensus as to the optimal design for each valvular disease has not been reached. Ideally, annuloplasty rings should allow natural mitral annular shape and dynamic motion without compromising repair durability. The objective of this study was to characterize more completely $\Phi$, the angle between the fibrous and muscular annular regions, and to assess the contribution of hinge motion to changes in mitral S-L dimension and annular area throughout the cardiac cycle. 


\begin{tabular}{|c|c|}
\hline \multicolumn{2}{|c|}{ Abbreviations and Acronyms } \\
\hline$\triangle \Phi$ & $\begin{array}{l}=\text { change in mitral annular hinge } \\
\text { angle }\end{array}$ \\
\hline$\Phi$ & $=$ mitral annular hinge angle \\
\hline 2D & $=2$-dimensional \\
\hline 2DFA & $=2$-dimensional fibrous annular area \\
\hline 2DMA & $\begin{array}{l}=2 \text {-dimensional muscular annular } \\
\text { area }\end{array}$ \\
\hline $2 \mathrm{DROC}_{\mathrm{xy}}$ & $\begin{aligned}= & 2 \text {-dimensional radius of curvature } \\
& \text { on xy plane }\end{aligned}$ \\
\hline 2DTA & $\begin{array}{l}=2 \text {-dimensional total mitral annular } \\
\text { area }\end{array}$ \\
\hline $3 \mathrm{D}$ & $=3$-dimensional \\
\hline 3DFA & $=3 \mathrm{D}$ fibrous annular area \\
\hline 3DMA & $=3 \mathrm{D}$ muscular annular area \\
\hline 3DTA & $\begin{array}{l}=3 \text {-dimensional total mitral annular } \\
\text { area }\end{array}$ \\
\hline $\mathrm{AH}$ & $=$ annular height \\
\hline AoP & $=$ aortic pressure \\
\hline $\mathrm{C}-\mathrm{C}$ & $=$ commissure to commissure \\
\hline$E_{A}-E_{P}$ & $=$ leaflet edge marker distance \\
\hline $\mathrm{ED}$ & $=$ end diastole \\
\hline ES & $=$ end systole \\
\hline $\mathrm{H}-\mathrm{L}$ & $=$ hinge axis to midlateral \\
\hline $\mathrm{H}-\mathrm{S}$ & $=$ hinge axis to saddle-horn \\
\hline IVC & $=$ isovolumic contraction \\
\hline IVR & $=$ isovolumic relaxation \\
\hline LA & $=$ left atrium \\
\hline LV & $=$ left ventricle \\
\hline LVP & $=$ left ventricular pressure \\
\hline S-L & $\begin{aligned}= & \text { septal (saddle-horn) to lateral } \\
& \text { (midlateral annulus) }\end{aligned}$ \\
\hline
\end{tabular}

\section{MATERIALS AND METHODS}

\section{Surgical Protocol}

All animals received humane care in accordance with institutional and federal guidelines and compliance with the Guide for the Care and Use of Laboratory Animals (www.nap.edu/catalog/5140.html). Seventeen adult, Dorsett-hybrid, male sheep ( $54 \pm 8 \mathrm{~kg}$ ) were medicated with ketamine ( 25 $\mathrm{mg} / \mathrm{kg}$ intramuscularly) for venous and arterial catheter placement and monitoring. Anesthesia was induced and maintained with inhalational isoflurane $(1 \%-2.5 \%)$ and supplemental oxygen. Through a left thoracotomy, 13 miniature tantalum radiopaque markers were implanted in the subepicardial wall of the left ventricle (LV) silhouetting the LV chamber (Figure 1, A). Through a left atriotomy with the animal on cardiopulmonary bypass (104 \pm 18 minutes) and antegrade cardioplegic arrest (64 \pm 10 minutes), 16 markers were sutured around the mitral annulus (M1-M16) and 2 at the anterior and posterior mitral leaflet edge along the central meridian $\left(\mathrm{E}_{\mathrm{A}}\right.$ and $\mathrm{E}_{\mathrm{P}}$, respectively, Figure 1, B). A micromanometer pressure transducer (PA4.5-X6; Konigsberg Instruments, Inc, Pasadena, Calif) was placed in the LV chamber through the left atrium (LA) and exteriorized.

\section{Data Acquisition}

Immediately after the operation, animals were transferred to the catheterization laboratory and studied in the right lateral decubitus position with the chest open. Two micromanometer-tipped pressure transducers (Millar Instruments; Houston, Tex) were calibrated and inserted into the LV and ascending aorta through a carotid artery catheter. A Konigsberg pressure transducer was calibrated against the 2 Millar pressure transducers while all transducers were in the LV; it was then pulled back into the LA, and the pressure was recorded. With the heart in normal sinus rhythm and ventilation transiently arrested at end expiration, simultaneous biplane videofluoroscopic images $(60 \mathrm{~Hz})$, electrocardiogram, LV pressure (LVP), aortic pressure (AoP), and LA pressure were recorded during a hemodynamically stable interval. At the completion of each study, biplanar images of a 3D helical phantom of known dimensions spanning the heart space were recorded. The 2-dimensional (2D) coordinates of each marker in each projected image were digitized frame by frame with semiautomated image processing and digitization software developed in our laboratory. ${ }^{12}$ Data from the 2 views were merged to yield the $3 \mathrm{D}$ coordinates for each marker with the helical phantom image data and custom software. ${ }^{13}$ The anatomic position of each marker was confirmed in each animal on necropsy.

\section{Data Analysis}

Hemodynamics and cardiac cycle timing. Three consecutive steady-state beats in sinus rhythm were selected from each study. Instantaneous LV volumes were calculated from the 3D coordinates of the subepicardial LV markers (Figure 1,A) by summing the volumes of multiple space-filling tetrahedra. Although this volume included both LV cavity and LV wall volumes, previous work has shown that relative changes in LV volume are accurately measured with this technique. ${ }^{14}$ For each cardiac cycle, a pressure-volume loop was used to define the time of end diastole (ED), end isovolumic contraction (IVC), end systole (ES), and end isovolumic relaxation (IVR). The timing of ES (the end of ejection) was confirmed to match the dicrotic notch associated with aortic valve closure. The timing of the $\mathrm{E}$ wave was defined as the first peak of leaflet marker separation $\left(\mathrm{E}_{\mathrm{A}^{-}}\right.$ $\mathrm{E}_{\mathrm{P}}$ distance; Figure 1, $B$ ); the A wave was defined as the timing of peak LA pressure during diastole (late LV filling). Valve closure was defined at the minimum $\mathrm{E}_{\mathrm{A}}-\mathrm{E}_{\mathrm{P}}$ distance.

Measurement of $\boldsymbol{\Phi}$. At each sample time, the 3D marker coordinates $(\mathrm{x}, \mathrm{y}$, and $\mathrm{z})$ were computed with the origin at the saddle-horn marker (M4 Figure $1, B)$, the positive $\mathrm{x}$-axis directed to the midlateral annular marker (M12; Figure 1, B), the positive z-axis directed to the LV apex marker (Figure $1, A$ ), and the positive $y$-axis defined by the cross product of the $\mathrm{x}$-axis and z-axis (right-hand coordinate system). M1 and M7 were located at the lateral edge of the fibrous trigones (adjacent to each commissure marker); the line between M1 and M7 was defined as the hinge axis. The fibrous annular plane was defined as a best-fit plane to the fibrous annular markers (M1 to M7, fibrous plane), and the muscular annular plane was defined as the best-fit plane of the muscular annular markers (M7-M16 and M1, muscular plane; Figure 1, $B$ ) with linear least-squares regression. This definition of planar surfaces allowed the definition of an angle, $\alpha$, that was calculated between the 2 planes, and the mitral annular $\Phi$ was defined as $\Phi=180-$ $\alpha$ (Figure 1, $A$ and $B$ ). Changes in $\Phi(\Delta \Phi)$ relative to ED were calculated; therefore $\Delta \Phi$ at ED was zero by definition.

Mitral annular profiles. Mitral annular profiles were described with orthographic drawings of mean data from all hearts in 3 different views: (1) aortic view, from the aorta to the lateral LV wall; (2) atrial view, from the LA into the LV; and (3) commissural view, from the anterior commissure toward the posterior commissure (Figure 4, $A, B$, and $C$, respectively). The radius of curvature of the saddle-horn region was calculated in 2D space on the xy plane $\left(2\right.$ DROC $\left._{x y}\right)$ with the saddle-horn marker (M4) and 2 adjacent markers (M3 and M5; Figure 4, $B$ ) to quantify changes in the shape of the saddle-horn region in the atrial view.

Mitral annular geometry. The S-L dimension of the mitral annulus was calculated as the distance between 2 lines, both parallel to the hinge axis: the first passing through the saddle-horn marker (M4) and the second passing through the midlateral marker (M12; Figure 1, B). The distances 

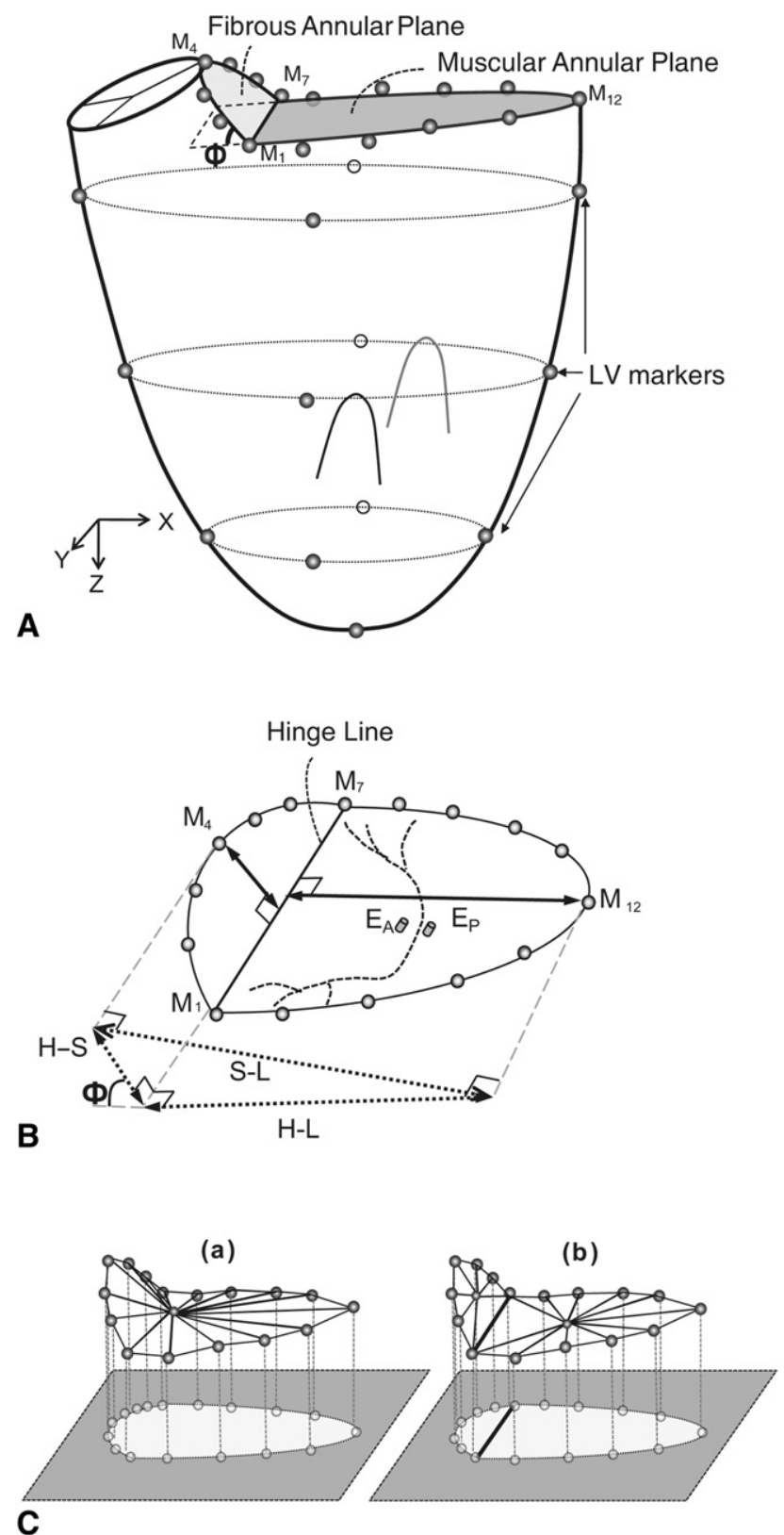

FIGURE 1. A, Schematic representation of marker array in left ventricle $(L V)$, mitral annulus, and leaflets. Best-fit plane is applied to fibrous annulus and muscular annulus. Angle from muscular plane to fibrous plane was defined as hinge angle $(\Phi)$. B, Mitral annular and leaflet markers, annular dimensions. $E_{A}$, anterior mitral leaflet midedge; $E_{P}$, posterior mitral leaflet midedge; $H-S$, hinge-saddle-horn dimension; $H-L$, hinge-lateral (muscular) dimension; $S$ - $L$, septal-lateral dimension. C, Schematic representations of 3-dimensional total mitral annular area $(a)$ and 3-dimensional muscular and fibrous areas $(b)$, with 2-dimensional projections on least squares-fit plane.

from the hinge axis to the saddle-horn marker $(\mathrm{H}-\mathrm{S})$ and to the midlateral marker (H-L) were designated the radii of the fibrous annulus and muscular annulus, respectively (Figure 1,B). The anterior-posterior C-C diameter was calculated as the distance between the 2 annular commissural markers (M8 and M16). Annular height (AH) was defined as the sum of the longest orthogonal distances above and below the annular plane: the distance to saddle-horn marker (M4) above the plane and the distance to the commissure markers M8 or M16, the lowest point of the mitral annulus. ${ }^{15}$ The total mitral annular area in 3D space (3DTA) was calculated as the sum of the area of 16 triangles formed by consecutive adjacent marker pairs on the annulus and the centroid of all annular markers (M1 to M16, Figure 1C-a). The 3D fibrous annular area (3DFA) was calculated in the same way as 3DTA, except the centroid of the fibrous annular marker subgroup was used (Figure 1,C). The 3D muscular annular area (3DMA) was calculated similarly (Figure 1, $C$ ). The projected total 2D mitral annular area (2DTA) was calculated from a projection of the annular markers onto the least-squares fit mitral annular plane. This was further subdivided into the fibrous (2DFA) and muscular (2DMA) fractional annular areas.

\section{Statistical Analysis}

All data are reported as mean \pm SD. Significant differences in $\Phi$ were determined by 2-tailed multiple $t$ tests with Bonferroni or Dunn correction. Multiple group comparisons at all cardiac cycle phases were made with 1and 2-way repeated measures analysis of variance with Bonferroni post hoc test (SigmaStat 3.5; SPSS, Inc, Chicago, Ill).

\section{RESULTS \\ Hemodynamics}

All animals were in hemodynamically stable condition and in normal sinus rhythm without the use of either positive or negative inotropic agents throughout data acquisition. The group average hemodynamic data were as follows: heart rate $88 \pm 12$ beats/min, $\mathrm{LVP}_{\mathrm{MAX}} 92 \pm 9 \mathrm{~mm} \mathrm{Hg}$, maximum derivative of pressure $1345 \pm 330 \mathrm{~mm} \mathrm{Hg} / \mathrm{s}, \mathrm{ED} L V P 13 \pm 3$ $\mathrm{mm} \mathrm{Hg}$, and ED volume $134 \pm 37 \mathrm{~mL}$ (including myocardial volume).

\section{Mitral Annular Hinge Angle}

Figure 2 shows raw $\Delta \Phi$ data for all animals $(\mathrm{n}=17)$, along with group mean LVP and AoP for 3 consecutive heartbeats as a function of percentage of cardiac cycle. During IVC and the concomitant rapid rise in LVP, $\Phi$ abruptly increased to a maximum (increased, or less flat, saddle shape). During ejection, $\Phi$ did not change throughout this period of high systolic pressure. During diastole, $\Phi$ fell with AoP, with most of the $\Phi$ decrease taking place during early filling before the $\mathrm{E}$ wave, followed thereafter by an undulating fall until ED.

Table 1 quantitatively summarizes $\Phi$ and $\Delta \Phi$ relative to ED at end IVC, ES, and end IVR. The $\Delta \Phi$ at end IVC was significantly larger (increased saddle shape, $18^{\circ} \pm 13^{\circ}, P<$ $.001)$. The $\Delta \Phi$ was relatively constant during ejection then decreased by $16^{\circ} \pm 6^{\circ}$ during early diastole until the $\mathrm{E}$ wave, when $\Delta \Phi$ was $2^{\circ} \pm 2^{\circ}$ (no difference vs ED or $\mathrm{A}$ wave).

Figure 3 shows the $\Phi, \mathrm{AH}, \mathrm{S}-\mathrm{L}, 3 \mathrm{DTA}$, and $\mathrm{E}_{\mathrm{A}}-\mathrm{E}_{\mathrm{P}}$ along with LVP, AoP, and LV volume in 3 consecutive cardiac cycles in a representative animal. AH change was very similar to $\Delta \Phi$ throughout the cardiac cycle, increasing abruptly during IVC, then decreasing during early diastole. During late filling, mitral S-L dimension and 3DTA decreased 


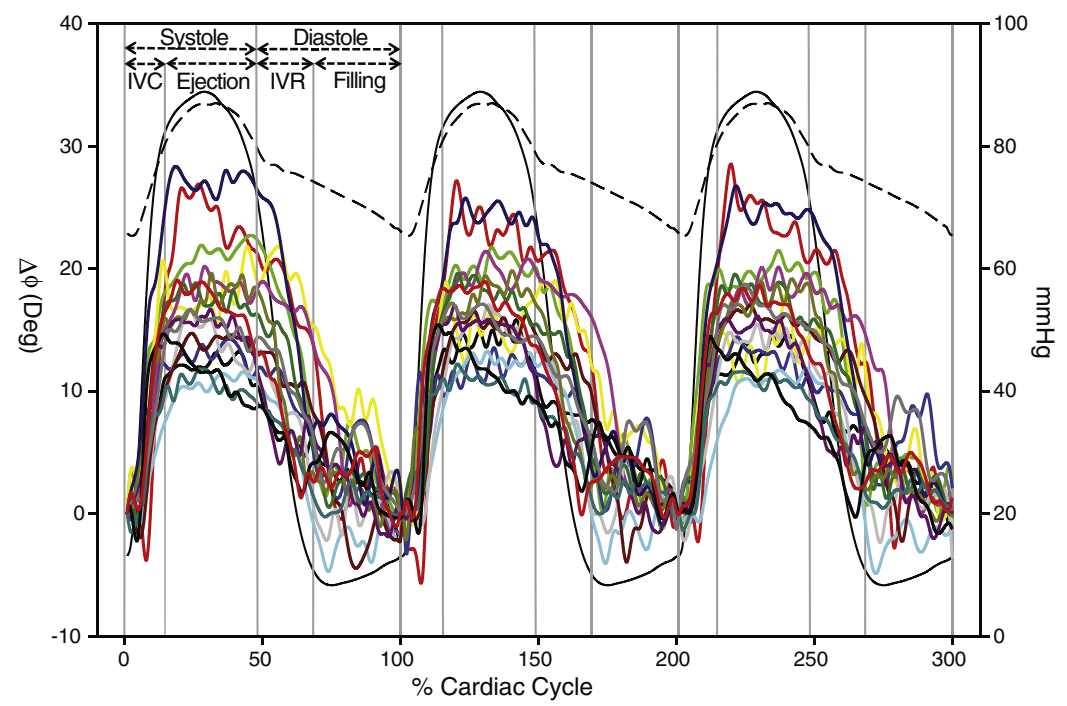

FIGURE 2. Hinge-angle change $(\Delta \Phi)$ in cardiac cycle. Changes in mitral hinge angle during 3 consecutive heart beats of all animals ( $\mathrm{n}=17$, raw data) normalized in percentage of cardiac cycles with mean left ventricular and aortic pressure curves. $I V C$, Isovolumic contraction; $I V R$, isovolumic relaxation.

and reached a minimum immediately before end IVC (preejection reduction). Similarly, $\Phi$ increased during IVC and reached a maximum at end IVC, suggesting the existence of related mechanisms between these parameters. Simultaneously, leaflet closure was observed from late diastole to early systole, and leaflets were completely closed (minimum $\mathrm{E}_{\mathrm{A}}-\mathrm{E}_{\mathrm{P}}$ distance), whereas the reduced S-L dimension and 3DTA were maintained during ejection.

\section{Alteration of Mitral Annular Shape}

Saddle shape. Mean mitral annular shape data $(\mathrm{n}=17)$ are shown in 3 orthographic views (Figure $4, A-C$ ). The $2 \mathrm{DROC}_{\mathrm{xy}}$ and $\mathrm{AH}$ dimension are summarized in Table $2 \mathrm{nu}-$ merically and as a percentage of the ED value. In the aortic view, the AH dimension increased significantly during systole by more than $30 \%$ and decreased to the baseline level almost entirely during early diastole (Figure $4, A$, and Table 2). In the atrial view, the $D$ shape of the annulus at ED was transformed into a kidney shape during systole, with the saddle-horn's inward motion toward the mitral centroid

TABLE 1. Quantitative summary of mitral annular hinge angle and its change relative to end diastole.

\begin{tabular}{lcc}
\hline & Hinge angle & Change \\
\hline End diastole & $61^{\circ} \pm 16^{\circ}$ & 0 \\
End isovolumic & $79^{\circ} \pm 20^{\circ} * \dagger$ & $18^{\circ} \pm 13^{\circ}$ \\
$\quad$ contraction & $78^{\circ} \pm 15^{\circ} * \dagger$ & $17^{\circ} \pm 7^{\circ}$ \\
End systole & $68^{\circ} \pm 15^{\circ} \dagger$ & $7^{\circ} \pm 7^{\circ}$ \\
End isovolumic & & \\
$\quad$ relaxation & $63^{\circ} \pm 16^{\circ}$ & $2^{\circ} \pm 2^{\circ}$ \\
E wave & $62^{\circ} \pm 16^{\circ}$ & 0 \\
A wave &
\end{tabular}

Data are mean $\pm \mathrm{SD} . * P<.001$ by 1-way RM ANOVA with Bonferroni correction; $\dagger v s \mathrm{ED}$, EndIVR, E wave, and A wave; †vs ED and A wave.
(Figure 4, B). During early filling, the muscular annulus expanded and exhibited its largest area during the $\mathrm{E}$ wave. The fibrous annulus returned nearly to its baseline shape during early filling. The $2 \mathrm{DROC}_{\mathrm{xy}}$ of the fibrous annulus was reduced by $45 \%$ during IVC and maintained during ejection, then returned to its baseline value during early diastole, which likely reflects the effect of aortic root expansion during systole on the regional deformation of the saddle-horn area. In the commissure view, the saddle shape was increased at ES (Figure 4, $C$ ). As the saddle-horn region was pushed toward the mitral centroid, the fibrous annulus was displaced away from the aorta. These observations characterize a flexible, regional motion of the saddle-horn coupled to the aortic root, being deformed in the xy plane, where both lateral sides are constrained by the presence of the rigid fibrous trigones.

S-L and C-C dimensions. Alterations in S-L, H-L, H-S, and $\mathrm{C}-\mathrm{C}$ dimensions are summarized in Table 2 numerically and as a percentage of the ED value, and mitral S-L reduction during IVC is schematically illustrated in Figure 5. The S-L dimension was 5\% larger during early filling $(P=.004)$. The mitral S-L dimension abruptly started falling during atrial systole, and $13 \%$ of the reduction occurred before ejection. S-L was static during ejection before returning nearly to its baseline during early diastole. The mitral H-L (muscular plane) dimension had a similar time course to the S-L dimension. The H-L dimension during early filling was even larger than at end IVR, meaning that the relaxed muscular annular dimension expanded maximally during early filling. The H-L dimension was $9 \%$ smaller during IVC, stable during ejection, and then returned to baseline. The H-S dimension (fibrous plane), however, did not show any statistically significant increase or decrease during the cardiac cycle. Thus the mechanism of S-L change consisted 


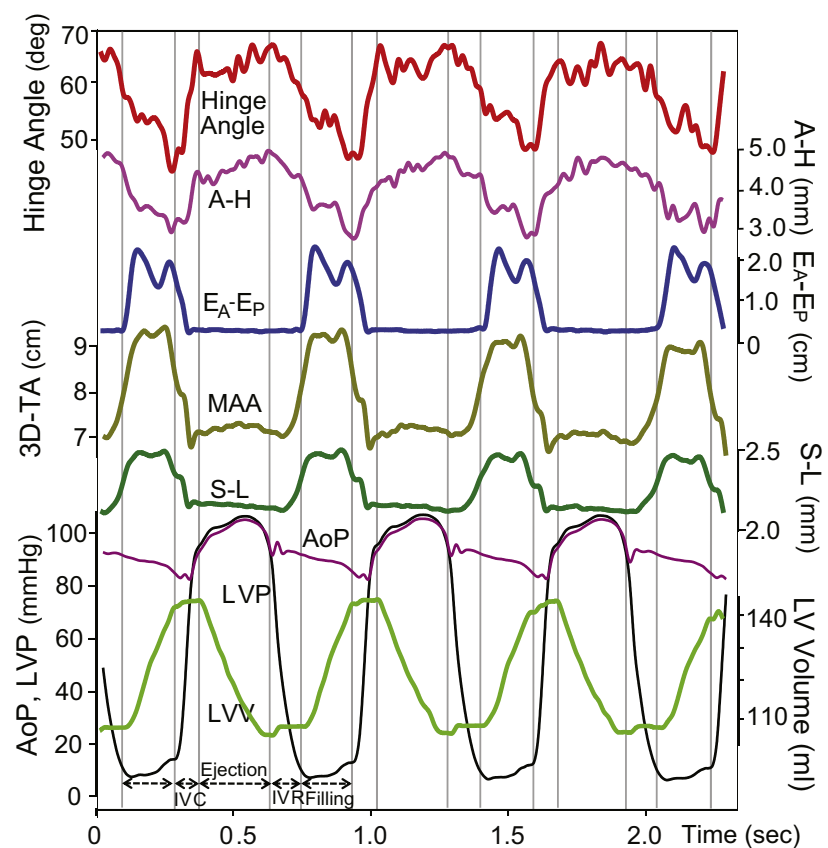

FIGURE 3. Mitral valve dynamics. Hinge angle, annular height $(A-H)$, leaflet edge marker distance $\left(E_{A}-E_{P}\right), 3$-dimensional total mitral annular area $(M A A, 3 D-T A)$, septal-lateral dimension $(S-L)$, with aortic pressure $(A o P)$, left ventricular pressure $(L V P)$, and left ventricular $(L V)$ volume $(L V V)$ throughout 3 cardiac cycles in representative heart. Note that hinge angle and annular height changes are quite similar, and most other parameters also change during isovolumic contraction or relaxation.

mainly of 2 dominant motions: (1) contraction and relaxation of the muscular annulus and (2) steepening and flattening of the fibrous annulus $\Phi$. The combination of these 2
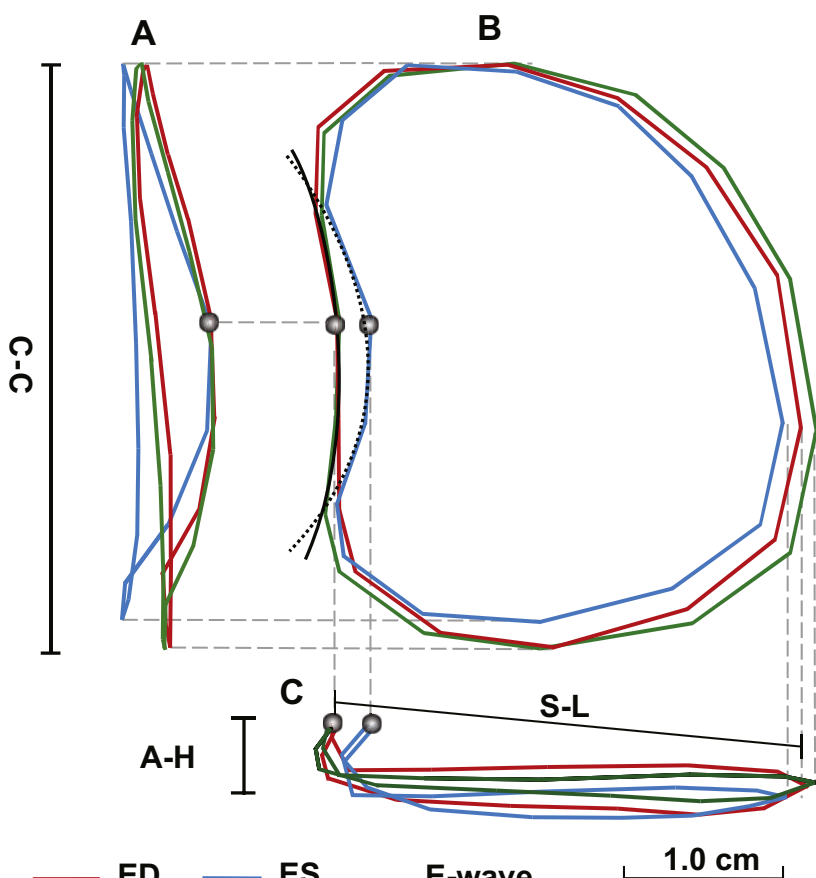

ED

ES

E-wave

$1.0 \mathrm{~cm}$

FIGURE 4. Mitral annular profiles in 3 orthographic drawings: A, Aortic view, as viewed from septum to lateral wall $(S-L)$; B, atrial view, as viewed from left atrium to left ventricle $(A-H)$; $\mathrm{C}$, commissure view, as viewed from anterior to posterior commissure $(C-C)$. Data are group mean $(\mathrm{n}=17)$ at end diastole $(E D, r e d)$, end systole ( $E S$, blue), and E wave (green). Marker indicates saddle-horn.

factors during IVC (H-L shortening by $9 \% \pm 5 \%$ and $\Delta \Phi 18^{\circ} \pm 13^{\circ}$ ) resulted in a $13 \% \mathrm{~S}$-L shortening before ejection began (Figure 5). The transformation from D to

TABLE 2. Two-dimensional radius of curvature, annular height, and septal-lateral, hinge-lateral, hinge-saddle, and commissure-commissure dimensions

\begin{tabular}{|c|c|c|c|c|c|c|}
\hline & ED & End IVC & ES & End IVR & E wave & A wave \\
\hline \multicolumn{7}{|l|}{ 2-Dimensional radius of curvature } \\
\hline Absolute $(\mathrm{cm}$, mean $\pm \mathrm{SD})$ & $6.8 \pm 6.5$ & $3.7 \pm 2.8^{*} \dagger$ & $3.4 \pm 2.9 * \ddagger$ & $5 \pm 4.2$ & $5.7 \pm 4.2$ & $5.6 \pm 4.4$ \\
\hline Relative to ED value (\%) & $100 \%$ & $54 \%$ & $50 \%$ & $74 \%$ & $84 \%$ & $82 \%$ \\
\hline \multicolumn{7}{|l|}{ Annular height } \\
\hline Absolute $(\mathrm{mm}$, mean $\pm \mathrm{SD})$ & $4.7 \pm 1.2$ & $5.8 \pm 1.4 * \S$ & $6.4 \pm 1.5 * \ddagger$ & $5.7 \pm 1.3 * \S$ & $5.3 \pm 1.3$ & $4.9 \pm 1.3$ \\
\hline Relative to ED value (\%) & $100 \%$ & $123 \%$ & $133 \%$ & $120 \%$ & $111 \%$ & $103 \%$ \\
\hline \multicolumn{7}{|l|}{ Septal-lateral dimension } \\
\hline Absolute $(\mathrm{cm}$, mean $\pm \mathrm{SD})$ & $2.4 \pm 0.3$ & $2.1 \pm 0.2 * \|$ & $2.1 \pm 0.3^{*} \|$ & $2.4 \pm 0.4$ & $2.5 \pm 0.3 * \dagger$ & $2.4 \pm 0.3$ \\
\hline Relative to ED value (\%) & $100 \%$ & $87 \%$ & $87 \%$ & $99 \%$ & $105 \%$ & $102 \%$ \\
\hline \multicolumn{7}{|l|}{ Hinge-lateral dimension } \\
\hline Absolute $(\mathrm{cm}$, mean $\pm \mathrm{SD})$ & $2.0 \pm 0.3$ & $1.8 \pm 0.3^{*} \|$ & $1.8 \pm 0.3^{*} \|$ & $2.0 \pm 0.3$ & $2.1 \pm 0.3^{*}$ & $2.0 \pm 0.3$ \\
\hline Relative to ED value (\%) & $100 \%$ & $91 \%$ & $89 \%$ & $100 \%$ & $106 \%$ & $103 \%$ \\
\hline \multicolumn{7}{|l|}{ Hinge-saddle dimension } \\
\hline Absolute $(\mathrm{cm}$, mean $\pm \mathrm{SD})$ & $0.7 \pm 0.2$ & $0.7 \pm 0.2$ & $0.8 \pm 0.2$ & $0.8 \pm 0.2$ & $0.7 \pm 0.2$ & $0.7 \pm 0.2$ \\
\hline Relative to ED value (\%) & $100 \%$ & $105 \%$ & $108 \%$ & $109 \%$ & $105 \%$ & $101 \%$ \\
\hline \multicolumn{7}{|c|}{ Commissure-commissure dimension } \\
\hline Absolute $(\mathrm{cm}$, mean $\pm \mathrm{SD})$ & $3.8 \pm 0.8$ & $3.7 \pm 0.7$ & $3.7 \pm 0.8$ & $3.7 \pm 0.8$ & $3.7 \pm 0.8$ & $3.7 \pm 0.8$ \\
\hline Relative to ED value (\%) & $100 \%$ & $98 \%$ & $97 \%$ & $98 \%$ & $99 \%$ & $101 \%$ \\
\hline
\end{tabular}

$\mathrm{ED}, \mathrm{E}$ wave, and A wave; $\S \mathrm{vs}$ ED and A wave; $\|$ vs ED, End IVR, E wave, and A wave; 9 vs ED and End IVR. 




FIGURE 5. Schematic representation of septal-lateral reduction during isovolumic contraction with mean data of change in hinge angle $(\Delta \Phi)$, hinge axis-midlateral dimension, and hinge axis-saddle-horn dimension.

kidney shape with the hinge motion of the saddle-horn region resulted in the acute $\Phi$ increase and contributed to S$\mathrm{L}$ reduction concurrent with muscular $\mathrm{H}-\mathrm{L}$ reduction during IVC. The $\Phi$ increase was also accompanied by an AH increase during IVC. Little C-C dimension change was observed throughout the cardiac cycle.

3D and 2D mitral annular areas. Annular hinge motion accounts for the contrasting pattern of area change between the 3DFA and 2DFA throughout the cardiac cycle. Table 3 summarizes the 3DMA, 3DFA, 3DTA, 2DMA, 2DFA, and 2DTA values numerically and as percentages of ED values. Figure 6 schematically represents these data at ED and ES. During atrial systole, the 3DMA reduced, reaching a minimum at end IVC (pre-ejection reduction) and remaining there during ejection. The 3DMA started to increase after ES, reached a maximum during early filling, and then gradually decreased in late filling. The 2DMA showed changes similar to the 3DMA. During atrial systole and IVC, the 3DFA, which shares a wall with the aortic root, increased during systole by $13 \%$ and decreased during diastole; however, the 2DFA showed the opposite change as a result of hinge motion. The 2DFA was reduced by approximately $30 \%$ during IVC, was unchanged during ejection, and then enlarged to its baseline value during IVR before LV filling. Furthermore, changes in the 3DTA and the 2DTA reflected changes in their respective muscular and fibrous annular areas. During late diastole and IVC, 3DTA fell because the 3DMA reduction was much greater than the 3DFA increase; moreover the 2DTA went down even more because both the 2DMA and 2DFA decreased. The contribution of the 2DFA change to the 2DTA change was substantial, given that the 2DFA accounted for only $11 \%$ of 2DTA but was responsible for $20 \%$ of 2DTA reduction during IVC.

\section{DISCUSSION}

The principal finding of this study is that $\Delta \Phi$ is an important mode of mitral annular deformation. It contributes substantially to systolic reduction and diastolic increase in mitral S-L dimension and 2DTA.

\section{Mitral Annular Motion}

Mitral annular hinge motion. This study builds on and extends our understanding of mitral annular dynamic motion reported previously. ${ }^{5,6,11,16}$ Dagum and colleagues ${ }^{11}$ fitted 2 planes, 1 each to the anterior and posterior mitral annular regions, and demonstrated results consistent with those

TABLE 3. Summary of muscular, fibrous, and total annular areas measured 2- and 3-dimensionally

\begin{tabular}{|c|c|c|c|c|c|c|}
\hline & ED & End IVC & ES & End IVR & E wave & A wave \\
\hline \multicolumn{7}{|l|}{ Muscular annular area } \\
\hline \multicolumn{7}{|l|}{ 3-Dimensional measurement } \\
\hline Absolute $(\mathrm{cm}$, mean $\pm \mathrm{SD})$ & $7.5 \pm 1.4$ & $6.6 \pm 2.0^{*} \dagger$ & $6.6 \pm 1.6^{* \dagger}$ & $7.7 \pm 1.7$ & $8.1 \pm 1.6^{*} \ddagger$ & $7.7 \pm 1.5$ \\
\hline Relative to ED value (\%) & $100 \%$ & $87 \%$ & $88 \%$ & $102 \%$ & $108 \%$ & $103 \%$ \\
\hline \multicolumn{7}{|l|}{ 2-Dimensional measurement } \\
\hline Absolute $(\mathrm{cm}$, mean $\pm \mathrm{SD})$ & $7.4 \pm 1.4$ & $6.6 \pm 2.0 * \dagger$ & $6.5 \pm 1.6^{* \dagger}$ & $7.6 \pm 1.7$ & $8.0 \pm 1.6 * \ddagger$ & $7.7 \pm 1.5$ \\
\hline Relative to ED value (\%) & $100 \%$ & $87 \%$ & $88 \%$ & $102 \%$ & $108 \%$ & $103 \%$ \\
\hline \multicolumn{7}{|l|}{ Fibrous annular area } \\
\hline \multicolumn{7}{|l|}{ 3-Dimensional measurement } \\
\hline Absolute $(\mathrm{cm}$, mean $\pm \mathrm{SD})$ & $1.6 \pm 0.6$ & $1.7 \pm 0.7$ & $1.8 \pm 0.7 * \S$ & $1.8 \pm 0.7 * \S$ & $1.7 \pm 0.6$ & $1.6 \pm 0.6$ \\
\hline Relative to ED value (\%) & $100 \%$ & $105 \%$ & $113 \%$ & $110 \%$ & $106 \%$ & $101 \%$ \\
\hline \multicolumn{7}{|l|}{ 2-Dimensional measurement } \\
\hline Absolute $(\mathrm{cm}$, mean $\pm \mathrm{SD})$ & $1.0 \pm 0.8$ & $0.8 \pm 0.8^{*} \dagger$ & $0.8 \pm 0.7^{* \dagger}$ & $1.0 \pm 0.8$ & $1.0 \pm 0.7$ & $1.0 \pm 0.7$ \\
\hline Relative to ED value (\%) & $100 \%$ & $69 \%$ & $71 \%$ & $100 \%$ & $101 \%$ & $100 \%$ \\
\hline \multicolumn{7}{|l|}{ Total annular area } \\
\hline \multicolumn{7}{|l|}{ 3-Dimensional measurement } \\
\hline Absolute $(\mathrm{cm}$, mean $\pm \mathrm{SD})$ & $9.1 \pm 1.3$ & $8.6 \pm 1.3 * \dagger$ & $8.4 \pm 1.5^{* \dagger}$ & $9.4 \pm 1.6$ & $9.8 \pm 1.4 * \dagger$ & $9.4 \pm 1.4$ \\
\hline Relative to ED value (\%) & $100 \%$ & $93 \%$ & $92 \%$ & $104 \%$ & $108 \%$ & $103 \%$ \\
\hline \multicolumn{7}{|l|}{ 2-Dimensional measurement } \\
\hline Absolute $(\mathrm{cm}$, mean $\pm \mathrm{SD})$ & $8.4 \pm 1.3$ & $7.4 \pm 1.8^{*} \dagger$ & $7.3 \pm 1.4^{*} \dagger$ & $8.6 \pm 1.5$ & $9.0 \pm 1.3^{* \ddagger}$ & $8.7 \pm 1.3$ \\
\hline Relative to ED value (\%) & $100 \%$ & $86 \%$ & $86 \%$ & $101 \%$ & $108 \%$ & $103 \%$ \\
\hline
\end{tabular}

$E D$, End diastole; $I V C$, isovolumic contraction; $E S$, end systole; $I V R$, isovolumic relaxation. $* P<.01$ by 2 -way RM ANOVA with Bonferroni correction; †vs ED, End IVR, E wave, and A wave; łvs ED; §vs ED and A wave. 


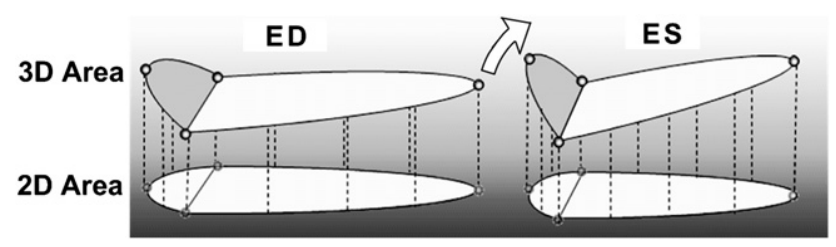

FIGURE 6. Schematic representations of 3-dimensional (3D) and 2-dimensional $(2 D)$ mitral annular area changes at end diastole $(E D)$ and end systole $(E S)$. Note that 2-dimensional fibrous annular area reduces as change in hinge angle increases.

reported here. With 8 markers, half the number of markers in this study, the anterior annulus was shown to steepen by approximately $7^{\circ}$ during systole, compared with $18^{\circ}$ in our study. The differences in marker density and hinge axis location most likely explain the previous smaller magnitude. Magnetic resonance studies of the mitral annulus qualitatively describe a dorsiflexion of the anterior half of the mitral annulus toward the lateral wall and quantitatively show a fitted plane on the entire mitral annulus tilted obliquely away from the LV outflow tract during systole. ${ }^{16}$ In this study, the commissural view (Figure 4,C) shows that the fibrous annulus curls away from the aorta during early systole and uncurls during early diastole. This same physiologic phenomenon corresponded in our study with $\Phi$ deformation. Our findings complement previous work by refining the methodology, using more discrete landmarks, and defining timing points during the cardiac cycle with pressure-volume loop analysis. In contrast, Kwan and associates ${ }^{5}$ indicated a flatter annulus at late systole than early systole in human beings with 3D echocardiography. This discrepancy may be due to differences in anatomic definitions between echocardiographic features and direct observation in the operating room during marker placement and to temporal definition differences between electrocardiographic and pressure-volume loop-derived time points.

Mitral annular shape change. Previous echocardiographic studies described the annulus as D shaped at ES in normal human subjects and in sheep with 3D-reconstructed representative samples. ${ }^{3,17}$ Our study, however, reveals that the saddle-horn region is almost straight in the C-C direction, and the entire mitral annular shape is D shaped at ED. In systole, the fibrous annulus is pushed inward toward the mitral annular centroid, resulting in a kidney shape at ES. This was quantitatively demonstrated by the radius of curvature of the saddle-horn annular region in the atrial view $\left(2 \mathrm{DROC}_{\mathrm{xy}}\right)$. Other previous studies have described the complex relationship between aortic root dynamics and mitral annular motion. ${ }^{4,18-20}$ Glasson and coworkers ${ }^{18}$ quantified shortening in the muscular annular segments but lengthening in 1 fibrous annular segment adjacent to the aortic root during systole. Dagum and associates ${ }^{4}$ and Lansac and colleagues ${ }^{21}$ reported that the ovine aortic root area expanded by $35 \%$ to $52 \%$ at the aortic commissure level and $40 \%$ to $50 \%$ at the aortic annular level during IVC. Dagum and associates $^{4}$ also showed that the left and noncoronary aortic sinuses at the commissure level enlarged circumferentially by $8.3 \%$ and $7 \%$, respectively. Our data support these findings by confirming the movement of the saddle-horn in toward the mitral valve centroid as a result of aortic root expansion during early systole, before ejection.

Mitral AH dynamics. Mitral AH change is determined more by $\Phi$ than by longitudinal stretch of the fibrous annular dimension. In this study, systolic AH increased by $36 \%$, while the longitudinal stretch in the fibrous annulus $(\mathrm{H}-\mathrm{S})$ did not change. Additionally, the timing of the $\mathrm{AH}$ increase entirely paralleled the $\Phi$ increase throughout the cardiac cycle. Previous studies described AH increases of $20 \%$ to $40 \%$ from ED to ES in normal ovine models, similar to our finding. ${ }^{15,22}$ Dagum and assoicates, ${ }^{4}$ however, found a uniform longitudinal elongation in all aortic sinuses of only $3 \%$ to $5 \%$ during IVC, which was accompanied by circumferential expansion of the aortic root. The normal mitral $\mathrm{AH}$ increase during systole is not explained by a small degree of aortic root longitudinal stretching but rather is due to the hinge motion of the fibrous annulus. This has implications for annuloplasty ring design. A dip in the muscular regions of the annulus near the commissures, as described by Timek and colleagues, ${ }^{15}$ also contributes to the AH increase, and the magnitude of the muscular dip is smaller with a Duran flexible complete ring and even smaller with a Physio semirigid, complete ring when compared with control values. Our results are consistent with previous evidence suggesting that stiffening or freezing the flexible hinge eliminates this hinge motion and thus AH change.

\section{Mechanisms of S-L Dimension and Annular Area Changes}

Contribution of hinge motion to $\mathrm{S}-\mathrm{L}$ dimension change. A central question prompted by this study is how important flexible hinge motion is to $\mathrm{S}-\mathrm{L}$ dimension reduction in a healthy heart. Both human and animal studies have revealed dynamic changes in the $\mathrm{S}-\mathrm{L}$ dimension throughout the cardiac cycle. ${ }^{5,9-11,17,23,24}$ Mitral S-L reduction is known to be important to achieve a competent valve during repair. ${ }^{23,25}$ Our results indicate that the major contributors to S-L dimension reduction are $\Delta \Phi$ and muscular annular contraction. Figure 7 illustrates 3 theoretic situations in the absence of flow considerations and pathophysiologic annular motion to illustrate the different components of annular motion described here. The fibrous plane $\Delta \Phi$ accounts for approximately half of the S-L reduction during systole. Figure 7, $A$, summarizes the theoretic changes in $\mathrm{S}-\mathrm{L}$ dimension at end IVC with a hinge fixed in the ED position $\left(\Phi=61^{\circ}\right)$. That is, if the mitral annulus lost its flexible hinge motion $(\Delta \Phi=0)$ but maintained muscular annular contraction, the $9 \%$ muscular region reduction would be the only factor contributing to mitral S-L dimension reduction and would result in only a $7 \%$ pre-ejection S-L reduction (Figure $7, A$ ). If 

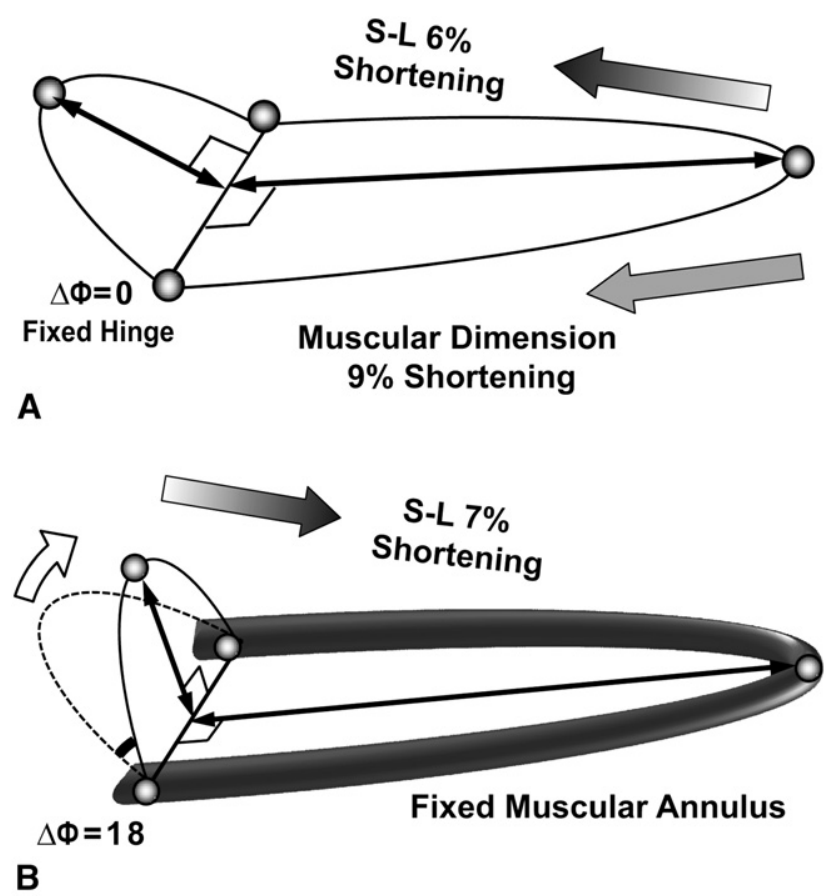

No S-L Shorteninge

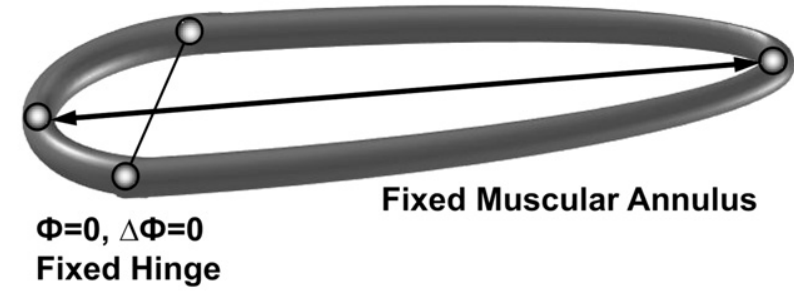

C

FIGURE 7. Schematic representations of speculative mitral annular dynamics with fixed hinge motion (A), fixed muscular annulus with partial annuloplasty ring $(\mathrm{B})$, and rigid complete ring $(\mathrm{C})$, derived from actual mean data of change in hinge angle $(\Delta \Phi)$, hinge axis-saddle horn dimension, and hinge axis-midlateral dimension. Note that contributions by hinge motion and hinge axis-midlateral dimension are almost equal to septal-lateral $(S-L)$ dimension change.

a partial rigid annuloplasty ring were implanted (Figure 7B), the muscular annulus would be fixed, and only the hinge motion would occur. Surprisingly, the S-L reduction would be $6 \%$, nearly equal to the contribution of the muscular annular contraction in this theoretic simulation. Finally, a complete, rigid annuloplasty ring would abolish all annular dynamic motion and result in no S-L reduction by either mechanism (Figure 7,C), possibly causing anterior mitral leaflet deformation. ${ }^{26}$ Our study shows that the contribution of flexible hinge motion to mitral S-L dimension change is substantial in the ovine heart, but the long-term clinical benefits, if any, of preserving this motion are not currently known.

Contribution of hinge motion to mitral annular area. Pre-ejection annular area reduction is an important mecha- nism for mitral valve leaflet competency. ${ }^{27}$ It is also known that inotropically induced mitral area reduction abolishes mitral insufficiency in functional mitral regurgitation. ${ }^{28}$ Measuring the dynamic mitral annular area, however, is challenging. Generally, there are 2 different ways to evaluate mitral annular area: (1) 2D projected area, which is used in most echocardiographic studies ${ }^{5,9,10,29,30}$ and disregards mitral annular nonplanarity and dynamic motion (Figure 1, C), ${ }^{30,31}$ and (2) 3D area measurement, usually assessed by summing multiple triangular areas created by fiducial markers or sonomicrometry crystals. ${ }^{11,32-34}$ Tsakiris and coworkers ${ }^{35}$ showed that posterior annular contraction principally contributed to mitral annular area contraction with $2 \mathrm{D}$ marker-projected area. In contrast, other studies have shown an increase in fibrous annular perimeter during systole, which implies that 3DFA may increase during systole. ${ }^{11,23,36}$ A specific analysis of each subarea with both 3D and 2D methods has never been performed, presumably because of insufficient radiopaque markers or sonomicrometer crystals or lack of discrete landmarks in echocardiographic studies. In our study, the 2DFA decreased by $30 \%$ during systole and was associated with fibrous annular hinge motion, in contrast to the 3DFA, which increased by $15 \%$ during systole. The 2D-projected annular area decreased by $12 \%$ during systole. A quarter of this reduction would be lost without hinge motion. Although this is a relatively small change compared with the 2DTA, it is not negligible relative to the entire area reduction. Furthermore, the effect of this flexible hinge motion is emphasized when muscular annular area change is constricted with a partial, flexible annuloplasty ring or band. ${ }^{11}$ Although long-term follow-up studies have shown that patients with a classic rigid ring have satisfactory survival and freedom from cardiac morbidity, ${ }^{37,38}$ it may be preferable to preserve native fibrous annular flexibility, especially for patients with normal mitral annular dynamics, LV systolic function, and physical activity (eg, type II leaflet motion). ${ }^{9,39,40}$ Previous studies have suggested that low transvalvular pressure gradients are present after annuloplasty with autologous pericardium, ${ }^{39}$ flexible ring, ${ }^{40}$ or semirigid band. ${ }^{9}$ The presence of flexible hinge motion may provide a mechanism for dynamic increases in LV filling and output during exercise. Further evaluation of blood flow kinematics with different annuloplasty ring shapes (eg, phase-contrast magnetic resonance imaging) and more long-term clinical data, however, are needed to demonstrate the clinical benefits, if any, of various ring shapes and flexibility.

\section{Study Limitations}

Several limitations of this animal study must be emphasized before extrapolating these observations to the human clinical context. These data were obtained in an acute, openchest setting in normal sheep hearts immediately after an open cardiac surgical procedure involving cardiopulmonary 
bypass. One disadvantage of this study was that we did not study diseased hearts but rather healthy ovine hearts. This allowed us to thoroughly study normal function with adequate statistical power but did not allow us to directly assess the pathophysiology of diseased hearts, with or without annuloplasty rings. This study also did not have markers on the aortic commissures or sinuses of Valsalva; thus the mitral-aortic interaction and the effect of aortic root dynamics can only be inferred from mitral annular markers, pressure curves, and temporal correlations. Certainly the differences in anatomy between the human and ovine mitral valve and subvalvular apparatus limit direct clinical applicability of this data; in light of the cited human echocardiographic and magnetic resonance imaging reports, however, it appears that human hearts do share this hinged mitral annular configuration.

\section{Clinical Implications}

These findings demonstrate that the fibrous mitral annulus is a dynamic structure that contributes to changes in mitral S$\mathrm{L}$ dimension, annular area, and $\mathrm{AH}$ throughout the cardiac cycle. Furthermore, the mitral annular saddle-horn region moves in toward the mitral valve centroid, probably as a result of the pre-ejection expansion of the aortic sinuses during early systole, and returns to its baseline position during early filling, thereby likely maximizing the LV inflow area dimension in concert with the muscular annulus. Fixing the flexible hinge motion with an annuloplasty ring would abolish the inherent hinge motion of the fibrous annulus that contributes to mitral S-L dimension and annular area reduction during systole. Long-term follow-up studies are required to clarify which patients could benefit most from preservation of this intrinsic annular hinge motion after ring annuloplasty. More elucidation of mitral annular hinge motion in human hearts and patients with various cardiac diseases may facilitate a more rational approach to ideal annuloplasty ring design in the future.

We acknowledge the superb technical assistance provided by Paul A. Chang, BA, Maggie Brophy, AS, Eleazar Briones, BA, Lauren Davis, BS, Sigurd Hartnett, BA, and Koji Arata, CCP.

\section{References}

1. Watanabe N, Ogasawara Y, Yamaura Y, Wada N, Kawamoto T, Toyota E, et al. Mitral annulus flattens in ischemic mitral regurgitation: geometric differences between inferior and anterior myocardial infarction: a real-time 3-dimensional echocardiographic study. Circulation. 2005;112(9 Suppl):I458-62.

2. O'Gara P, Sugeng L, Lang R, Sarano M, Hung J, Raman S, et al. The role of imaging in chronic degenerative mitral regurgitation. JACC Cardiovasc Imaging. 2008;1:221-37.

3. Ryan LP, Jackson BM, Parish LM, Plappert TJ, St John-Sutton MG, Gorman JH 3rd, et al. Regional and global patterns of annular remodeling in ischemic mitral regurgitation. Ann Thorac Surg. 2007;84:553-9.

4. Dagum P, Green GR, Nistal FJ, Daughters GT, Timek TA, Foppiano LE, et al. Deformational dynamics of the aortic root: modes and physiologic determinants. Circulation. 1999;100(19 Suppl):II54-62.
5. Kwan J, Qin JX, Popovic ZB, Agler DA, Thomas JD, Shiota T. Geometric changes of mitral annulus assessed by real-time 3-dimensional echocardiography: becoming enlarged and less nonplanar in the anteroposterior direction during systole in proportion to global left ventricular systolic function. J Am Soc Echocardiogr. 2004; 17:1179-84.

6. Ahmad RM, Gillinov AM, McCarthy PM, Blackstone EH, Apperson-Hansen C, Qin JX, et al. Annular geometry and motion in human ischemic mitral regurgitation: novel assessment with three-dimensional echocardiography and computer reconstruction. Ann Thorac Surg. 2004;78:2063-8.

7. Votta E, Maisano F, Bolling SF, Alfieri O, Montevecchi FM, Redaelli A. The Geoform disease-specific annuloplasty system: a finite element study. Ann Thorac Surg. 2007;84:92-101

8. Daimon M, Fukuda S, Adams DH, McCarthy PM, Gillinov AM, Carpentier A, et al. Mitral valve repair with Carpentier-McCarthy-Adams IMR ETlogix annuloplasty ring for ischemic mitral regurgitation: early echocardiographic results from a multi-center study. Circulation. 2006;114(1 Suppl):I588-93.

9. Sharony R, Saunders PC, Nayar A, McAleer E, Galloway AC, Delianides J, et al. Semirigid partial annuloplasty band allows dynamic mitral annular motion and minimizes valvular gradients: an echocardiographic study. Ann Thorac Surg. 2004; 77:518-22.

10. Dall'Agata A, Taams MA, Fioretti PM, Roelandt JR, Van Herwerden LA. Cosgrove-Edwards mitral ring dynamics measured with transesophageal three-dimensional echocardiography. Ann Thorac Surg. 1998;65:485-90.

11. Dagum P, Timek T, Green GR, Daughters GT, Liang D, Ingels NB Jr, et al. Threedimensional geometric comparison of partial and complete flexible mitral annuloplasty rings. J Thorac Cardiovasc Surg. 2001;122:665-73.

12. Niczyporuk MA, Miller DC. Automatic tracking and digitization of multiple radiopaque myocardial markers. Comput Biomed Res. 1991;24:129-42.

13. Daughters GT, Miller DC, Schwartzkopf A, Mead CW, Ingels NB Jr. A comparison of two analytical systems from three-dimensional reconstruction from biplane videoradiograms. Proc Comp Cardiol (IEEE). 1989;15:79-82.

14. Moon MR, DeAnda A Jr, Daughters GT 2nd, Ingels NB Jr, Miller DC. Experimental evaluation of different chordal preservation methods during mitral valve replacement. Ann Thorac Surg. 1994;58:931-44.

15. Timek TA, Glasson JR, Lai DT, Liang D, Daughters GT, Ingels NB Jr, et al. Annular height-to-commissural width ratio of annuloplasty rings in vivo. Circulation. 2005;112(9 Suppl):I423-8, 30.

16. Komoda T, Hetzer R, Siniawski H, Oellinger J, Felix R, Uyama C, et al. Effects of prosthetic valve placement on mitral annular dynamics and the left ventricular base. ASAIO J. 2001;47:60-5.

17. Kaplan SR, Bashein G, Sheehan FH, Legget ME, Munt B, Li XN, et al. Threedimensional echocardiographic assessment of annular shape changes in the normal and regurgitant mitral valve. Am Heart J. 2000;139:378-87.

18. Glasson JR, Komeda MK, Daughters GT, Niczyporuk MA, Bolger AF, Ingels NB, et al. Three-dimensional regional dynamics of the normal mitral anulus during left ventricular ejection. J Thorac Cardiovasc Surg. 1996;111:574-85.

19. Lansac E, Lim HS, Shomura Y, Lim KH, Rice NT, Goetz W, et al. A four-dimensional study of the aortic root dynamics. Eur J Cardiothorac Surg. 2002;22: 497-503.

20. Timek TA, Green GR, Tibayan FA, Lai DT, Rodriguez F, Liang D, et al. Aortomitral annular dynamics. Ann Thorac Surg. 2003;76:1944-50.

21. Lansac E, Lim HS, Shomura Y, Lim KH, Rice NT, Goetz WA, et al. Aortic root dynamics are asymmetric. J Heart Valve Dis. 2005;14:400-7.

22. Gorman JH 3rd, Gorman RC, Jackson BM, Enomoto Y. St John-Sutton MG, Edmunds LH Jr. Annuloplasty ring selection for chronic ischemic mitral regurgitation: lessons from the ovine model. Ann Thorac Surg. 2003;76:1556-63.

23. Tibayan FA, Rodriguez F, Langer F, Zasio MK, Bailey L, Liang D, et al. Annular remodeling in chronic ischemic mitral regurgitation: ring selection implications. Ann Thorac Surg. 2003;76:1549-55.

24. Glasson JR, Green GR, Nistal JF, Dagum P, Komeda M, Daughters GT, et al. Mitral annular size and shape in sheep with annuloplasty rings. J Thorac Cardiovasc Surg. 1999;117:302-9.

25. Timek TA, Lai DT, Tibayan F, Liang D, Daughters GT, Dagum P, et al. Septallateral annular cinching abolishes acute ischemic mitral regurgitation. $J$ Thorac Cardiovasc Surg. 2002;123:881-8.

26. Salgo IS, Gorman JH 3rd, Gorman RC, Jackson BM, Bowen FW, Plappert T, et al. Effect of annular shape on leaflet curvature in reducing mitral leaflet stress. Circulation. 2002;106:711-7.

27. Timek T, Dagum P, Lai DT, Green GR, Glasson JR, Daughters GT, et al. The role of atrial contraction in mitral valve closure. J Heart Valve Dis. 2001;10:312-9. 
28. Keren G, Laniado S, Sonnenblick EH, Lejemtel TH. Dynamics of functional mitral regurgitation during dobutamine therapy in patients with severe congestive heart failure: a Doppler echocardiographic study. Am Heart J. 1989;118:748-54.

29. Flachskampf FA, Chandra S, Gaddipatti A, Levine RA, Weyman AE, Ameling W, et al. Analysis of shape and motion of the mitral annulus in subjects with and without cardiomyopathy by echocardiographic 3-dimensional reconstruction. J Am Soc Echocardiogr. 2000;13:277-87.

30. van Rijk-Zwikker GL, Mast F, Schipperheyn JJ, Huysmans HA, Bruschke AV. Comparison of rigid and flexible rings for annuloplasty of the porcine mitral valve. Circulation. 1990;82(5 Suppl):IV58-64.

31. Levine RA, Handschumacher MD, Sanfilippo AJ, Hagege AA, Harrigan P, Marshall JE, et al. Three-dimensional echocardiographic reconstruction of the mitral valve, with implications for the diagnosis of mitral valve prolapse. Circulation. 1989;80:589-98.

32. Timek TA, Miller DC. Experimental and clinical assessment of mitral annular area and dynamics: what are we actually measuring? Ann Thorac Surg. 2001;72: 966-74.

33. Kaji S, Nasu M, Yamamuro A, Tanabe K, Nagai K, Tani T, et al. Annular geometry in patients with chronic ischemic mitral regurgitation: three-dimensional magnetic resonance imaging study. Circulation. 2005;112(9 Suppl):I409-14.

34. Lansac E, Hiang K, Shomura Y, Goetz WA, Sen Lim H, Rice NT, et al. Dynamic balance of the aortomitral junction. $J$ Thorac Cardiovasc Surg. 2002; 123:911-8.

35. Tsakiris AG, Gordon DA, Mathieu Y, Irving L. Motion of both mitral valve leaflets: a cineroentgenographic study in intact dogs. J Appl Physiol. 1975;39: 359-66.

36. Parish LM, Jackson BM, Enomoto Y, Gorman RC, Gorman JH 3rd. The dynamic anterior mitral annulus. Ann Thorac Surg. 2004;78:1248-55.

37. Braunberger E, Deloche A, Berrebi A, Abdallah F, Celestin JA, Meimoun P, et al. Very long-term results (more than 20 years) of valve repair with Carpentier's techniques in nonrheumatic mitral valve insufficiency. Circulation. 2001;104(12 Suppl. 1):I8-11.

38. Chauvaud S, Fuzellier JF, Berrebi A, Deloche A, Fabiani JN, Carpentier A. Longterm (29 years) results of reconstructive surgery in rheumatic mitral valve insufficiency. Circulation. 2001;104(12 Suppl. 1):I12-5.

39. Borghetti V, Campana M, Scotti C, Domenighini D, Totaro P, Coletti G, et al. Biological versus prosthetic ring in mitral-valve repair: enhancement of mitral annulus dynamics and left-ventricular function with pericardial annuloplasty at long term. Eur J Cardiothorac Surg. 2000;17:431-9.

40. Okada Y, Shomura T, Yamaura Y, Yoshikawa J. Comparison of the Carpentier and Duran prosthetic rings used in mitral reconstruction. Ann Thorac Surg. 1995;59:658-63.

\section{Discussion}

Dr R. W. M. Frater (Bronx, $N Y$ ). With respect to what I understand to be your diagram of a full rigid ring, in fact there aren't any full rigid rings that have a curved portion at the base of the anterior leaflet. So this is basically a false concept. There is not a rigid ring that has that kind of shape. Rigid rings have a straight line there. In fact, it is a straight line in rigid rings from one trigone to the next. So I grant you that a rigid ring does significantly affect the outflow tract, it stops the normal motion of the subaortic curtain toward the mitral muscular annulus, but it isn't shaped like that. So I think, you know, you need to be accurate if you want to compare rigid rings with partially rigid rings.

I gather that you are saying, and I agree with you completely here, that there is a motion in this direction and that it changes that angle. I think it has very little to do with how the mitral valve closes, however, for the simple reason that the mitral valve anterior leaflet hinges across this line. It doesn't hinge up here. It hinges here. So this motion helps to make the annulus smaller but does relatively little to the coaptation area of a normal mitral valve.

I am sorry to be so critical, but I hope you perceive these as questions and perhaps can answer them.

Dr Itoh. Thanks for the comments. I completely agree with you about the ring shape. When I look at the Physio ring or whatever we have, the shape of this portion is definitely straight, but this is kind of exaggerated. So I don't mean to make this kind of curve.

Also, the contribution of this normal intrinsic motion to the S-L reduction and also mitral annular area is, as you pointed out, kind of little and it doesn't probably matter. It might be true, but when I calculated S-L reduction as well as the mitral annular area, which is in the article, this motion contribution is calculated as half of the normal amount of the physiologic $13 \%$ reduction. If we could preserve all this natural intrinsic function, I believe it might help lifelong, like perfect mitral valvuloplasty, which Dr Carpentier mentioned yesterday; he always prefers the patient not to need further surgery for 20 or 30 years. Of course, his long-term results are totally satisfactory, but there might be something we can do here.

Dr Gus J. Vlahakes (Boston, Mass). In the graphics in the presentation, you are modeling the saddle-horn region as flat. In fact, is it not curvilinear toward the posterior annulus as a result of the anterior bulging? From your article and from your presentation, it appears that your model represents this region being flat and in a single plane.

Dr Itoh. Yes, you are right. This is not a plane. So the plane shown is just a best-fit plane. Of course, all the saddle-horn is more bumpy and an irregular shape. Yes, this is just a calculation.

Dr Vlahakes. The line where you are measuring the angle also corresponds to where basal strut chordae may insert. Do you think they have any function in creating this phenomenon that you have observed?

Dr Itoh. That is a good question. We actually didn't calculate any strut chordae. We do have markers on the papillary muscle tip and the basal chordae, but we didn't think about that kind of additional function of the second-order chordae. So that might be a good suggestion for our future calculations. Thank you very much.

Dr John S. Ikonomidis (Charleston, SC). I think this article is interesting because it illustrates some of the interesting interactions between the aortic root and the aortomitral continuity, which is something that I don't think we think about a lot. But stepping away from the mitral valve for a second, I wonder if you would care to comment on the effect of aortic root replacement on the mitral valve? You are suggesting that $\Phi$ is related to aortic root dilatation during isovolumic contraction of the LV; therefore, what is the long-term effect on the mitral valve if you replace the aortic root and presumably take away that change in $\Phi$ ?

Dr Itoh. That is a very interesting subject, I think. Dr Miller always does the aortic root operation, cinch down the aortic annulus, but of course, when you cut all the sinuses of Valsalva and put the artificial graft, you are going to flatten the configuration of the aortic root. So it might affect mitral valvular motion, and that is also going to be in our future study. 